RIVISTA DEL NUOVO CIMENTO

N. 4,1970

VOLLME II

\title{
Electrodynamies of Pulsars.
}

B. BER'TOTTI

European Space Research Institute - Frascati

(Rivista del Nuovo Cimento, 2, 102 (1970))

The caption of Fig. 2 on p. 107 should read "The profiles of the consecutive radio pulses of CP $0328 \ldots$...

In eq. (20) the bounds for the density $n$ should read

$$
\begin{aligned}
& 10^{11} \leqslant n \leqslant 4 \cdot 10^{16} \mathrm{~cm}^{-3}, \\
& 10^{4} \leqslant n \leqslant 4 \cdot 10^{8} \mathrm{~cm}^{-3} .
\end{aligned}
$$

